\title{
Value of digital information networks: a holonic framework
}

\author{
António Madureira • Nico Baken • \\ Harry Bouwman
}

Accepted: 26 January 2011 / Published online: 9 February 2011

(C) The Author(s) 2011. This article is published with open access at Springerlink.com

\begin{abstract}
The worldwide extraordinary level of interest in digital information networks' deployment among nations is due to the strong perception that they bring economic, social and environmental value. Our literature review on studies aiming at clarifying the value of information networks, led us to conclude that these studies take speculative, elusive or limited conclusions. We identify the requirements to capture the value of information networks and indicate a possible theoretical ground to account for it. Based upon this, we propose a framework operationalized with data from Eurostat. Furthermore, we identify the added-value of our framework with a precise and comprehensive comparison with two state of the art reference frameworks. We demonstrate that our framework provides significant conceptual addedvalue and, more fundamentally, allows for traditional measures of economic value (e.g. productivity and growth), as well as for other measures of value
\end{abstract}

\footnotetext{
A. Madureira $(\varangle) \cdot$ N. Baken

Network Architectures and Services (NAS) Group,

Delft University of Technology,

Delft, The Netherlands

e-mail: a.j.pintosoaresmadureira@tudelft.nl

N. Baken

Corporate Strategy and Innovation Department, Royal KPN,

Den Haag, The Netherlands

e-mail: nico.baken@kpn.com

H. Bouwman

Faculty of Technology, Policy, and Management,

Section of Information \& Communication Technology,

Delft University of Technology,

Delft, The Netherlands

e-mail: w.a.g.a.bouwman@tudelft.nl
} 
(e.g. social and environmental). Finally, we demonstrate with examples the wider application range of our framework in comparison with existing work.

Keywords Digital · Information • Network • Evolution · Framework • Value

\section{Introduction}

Since the 1980s, the telecommunication sector has been expanding rapidly [151]. The exponential growth of telecommunication-supported information network services can be explained by many factors, including technological advancements, market liberalization and privatizations. The worldwide extraordinary level of interest in information networks' deployment among nations is due to the strong perception that information networks bring economic, social and environmental benefits [66]. Some authors speculate that information networks may have a similar impact as transport networks had during the 20th century [129]. Digital information networks, and more generally Information Technology (IT), constitute the basis of a new technology driven economic era. In long wave theory, this era is known as the 5th Kondratieff economic cycle [133] and manifests itself by a sinusoidal-like longterm cycle from approximately 40 to 60 years in length with a semi-period of high productivity growth followed by a semi-period of relatively slow growth [70]. The benefits of digital information networks have both a quantitative nature (e.g. deployment of the infrastructure) and a qualitative nature (e.g. better quality of health care services, improved education and organizational efficiency). Policy makers have for long expressed this perception upon the value of information networks [178]. The Organisation for Economic Cooperation and Development (OECD) considered broadband as key to enhancing competitiveness and sustaining economic growth [129]. Many governments are increasingly committed to extending information networks to their citizens [96], particularly in the developing nations [93]. Consequently, the levels of interdependency between users and information network providers increased dramatically [51] and the information network infrastructure became an essential facility for other sectors.

The contribution of this article is as follows. In Section 2, we describe: a) two paradigmatic views on the value of information: orthodox and evolutionary economics; b) the major conclusions of a thorough literature review of 23 studies spanning the years 1980-2009 aiming at clarifying the value of information networks; c) the major conclusions of a thorough literature review of 38 studies on the value of IT in general (with hard- and software); and d) a set of requirements for any framework aiming at capturing the value of information networks. In Section 3, we provide a theoretical background to account for these requirements and a novel framework to address the value of information networks. In Section 4, we compare our framework with two reference frameworks and we discuss the empirical validation and application 
of our framework. In Section 5, we conclude by resuming our contribution, limitations of our work and possible future developments.

In order to support further investments in digital information network infrastructures (e.g. in Fibre To The Home (FTTH)), it is necessary to justify expenditures that have already been made and demonstrate their value. The framework described in this article adds up significant conceptual and applied value in comparison with previous work in the field. Therefore, it is an essential input for policy makers in the development of private and public information network-related policies. A preliminary impression of our work was presented in [110] and extended in this article with a complete description of our framework.

\section{State of the art}

\subsection{Orthodox and evolutionary economics}

Two views can be distinguished to account for the value of information networks [27]: the orthodox economic approach and the evolutionary economic approach. The orthodox economic approach views information as an observable production input changing the uncertainty regarding the performance of an economic system. In this context, the value of information is the difference between an informed economic system and a less informed economic system. For example, in [100], information was observed by measuring the broadband penetration rate and the economic system performance was observed by measuring economic growth. The value of information was measured by the correlation between the broadband penetration rate and the economic growth.

The evolutionary economic approach views information as procedures to change the nature of an economic system. In this context, the value of information is the difference between the results obtainable by invoking procedures from one economic system to that of another [171]. For example, recruiting agencies have multiple procedures to locate, evaluate and place job candidates. An information procedure has value if it changes the obtainable results for the better.

The orthodox view of an economic system is coarse grain as a black box transforming inputs into outputs. The evolutionary view is finer grain: modular input procedures can be rearranged to rearrange outputs. The orthodox view helps understanding the value of information networks as facts from observations. The evolutionary view helps understanding the value of information networks as procedures leading to changes in observations. The orthodox view applies statistical inference to the observations. The evolutionary view applies rule based logic to construct paths with modularity, robustness, search and connectivity through a collection of problems. From this perspective, the evolutionary approach extends logically to flows and information networks. Descriptions of economic systems are typically orders of magnitude larger in evolutionary economics than in orthodox economics. Thus, it is not 
uncertainty, but complexity or computational costs to generate and search an enormous space state of information procedure possibilities that concerns evolutionary researchers.

Kallinikos, in an attempt to understand the complex character of technologically sustained information processes, takes some conclusions about the nature of information: information is self-referential and non-foundational [94]. Self-referential in the sense that for information to have value it must be able to add a difference to what is already known. Using words of Borgman: "to be told that the sun will rise tomorrow is to receive no information. To learn that one has won the jackpot in the lottery is to have great news" [19]. Non-foundational in the sense that informational differences emerge through comparison of two or more objects or items, thus, are not singular, but relational entities. The central criticism to the orthodox approach is that it fails to picture the fundamental nature of information and of the economic agent as an information processing entity [55]. Doing so, it misstates the nature of reality, not in a marginal way, but in a fundamental way.

\subsection{Literature on the value of information networks}

Information networks do not act in economy by themselves, but in conjunction with other IT (primarily consisting of hard- and software). Therefore, the separability of the value of information networks is not an elementary task and most of the research done aims at understanding the general value of IT. We reviewed 23 studies, from 1980 to 2009, focusing on the value of information networks and they all have an orthodox economic character. We just present here the major conclusions (further details can be provided upon request).

These studies can be grouped into three classes: 1) macro-economic type of studies using general equilibrium theories and/or input-output tables [1, 36, $43,78,81,96,141]$; 2) econometric type of studies not addressing the issue of causality [45, 48, 56, 79, 103, 104, 107, 108, 150, 160, 168, 169]; and 3) econometric type of studies claiming to address causality $[46,68,100,151]$.

The usefulness of the models from the first class comes from the fact that they provide policy analysts a tool to study the effect of information networks across the interdependencies and feedbacks of an economy [18]. But due to the nature of the underlying assumptions (e.g. perfectly rational behaviour and equilibrium solutions), empirical validation is not addressed [63]. Hence, claims such as "the economic impact of broadband development over a ten year period in Germany amounts to 968,000 additional jobs" [96] tend to have a speculative character.

Madden and Savage found that the causality between information networks and economic growth is generally in both directions [107]. Similarly Shiu and Lam observed a "bidirectional relationship between telecommunications development and economic growth for European countries and those belonging to the high-income group" [151]. Thus, causality is a methodological challenge inherent in disentangling the value of information networks. This is obvious, 
given the self-referential character of information referred to above. Thus, all the results of these studies should be interpreted cautiously.

Recently, some econometric studies have claimed to address the issue of causality. However, in orthodox economics, causality is traditionally considered redundant or methodologically impeding. Thus, either it is simply left apart or it is given a deterministic interpretation which strips it of its original substance [54]. On the other hand, evolutionary economics stands upon finer grain procedural descriptions of causal paths which led to a much more sophisticated and realistic concept of causality (circular and cumulative causality pioneered by Thorstein Veblen in 1898 [145]). It is symptomatic that, for example Koutroumpis in 2009, claimed important direct benefits from broadband to economic growth, the actual intermediating processes were not clarified [100].

\subsection{Literature on the value of IT}

We also reviewed 38 studies on the value of IT (including hard- and software). The first studies on the value of IT provided equivocal results. For example, Santos et al. evidence that, on average, IT investments are zero Net Present Value (NPV) investments, thus, they are worth as much as they cost [146]. These earlier studies have led to the IT productivity paradox, best stated by Robert Solow's famous quote in 1987: "you can see the computer age everywhere but in the productivity statistics". In 1996, Hitt and Brynjolfsson resumed the status quo stating that "while some authors have attributed large productivity improvements and substantial consumer benefits to IT, others report that IT has not had any bottom line impact on business profitability" [85]. The same authors in the same year proclaimed the end of the IT productivity paradox after verifying that IT spending has made a substantial and statistically significant contribution to firm output in their dataset including 367 large firms [24].

Despite this claim from Brynjolfsson and Hitt, the subsequent studies were cautions about the end of the IT productivity paradox. Mitra and Chaya found out that IT investments are associated with lower average production costs, lower average total costs and higher average overhead costs [122]. Byrd and Marshall mention that the "direct linkage between technology investment and increase in organizational performance and productivity has been extremely elusive" [32]. In 2000, Brynjolfsson and Hitt raised the issue of causality reviving serious doubts about the positive results obtained until then [25]. They suggested that the link between IT and increased productivity emerged well before the recent surge in the aggregate productivity statistics and that the current macro-economic productivity revival may in part reflect the contributions of intangible capital accumulated in the past. Sircar et al. express the view at the time stating "there have been several attempts in the past to assess the impact of information technology on firm performance that have yielded conflicting results" [156] (see also [167]). Carr in 2003, referring to IT management, stated that "the key to success, for the vast majority 
of companies, is no longer to seek advantage aggressively but to manage costs and risks meticulously" [34]. Some attempts were made to improve the econometric results by observing different variables related with IT and performance $[85,156,163]$. For example, [156] investigated statistical relations between seven input measures of IT and corporate investments with seven measures of firm performance using a large database consisting of over 2,000 observations of 624 firms.

All the previous research mentioned treats IT as one whole system much in line with the orthodox economic approach. A more advanced stream of literature, more in line with evolutionary economics, attempts to depict the value of particular subcomponents of IT [6, 27, 102, 144]. For example, [144] used a multi-theoretic lens to argue that IT investments and capabilities influenced firm performance through three significant organizational capabilities (agility, digital-options and entrepreneurial-alert) and strategic processes (capabilitybuilding, entrepreneurial action and co-evolutionary adaptation). With these more specific studies, recognized scientific fields emerged in the information economic domain.

A particular important one was Transaction Cost Economics (TCE) which analyzed the value of IT in terms of its impact on transaction costs and coordination risks. Zaheer and Venkatraman, drawing on theoretical and empirical research on transaction costs, developed and tested a model of the determinants of the degree of electronic integration in the commercial segment of the property and casualty industry [180]. Based on a sample of 120 independent agencies, they provided empirical support for three hypotheses on the determinants of electronic integration. Garicano and Kaplan investigated the changes in transaction costs from the introduction of the Internet in transaction between firms Business To Business (B2B) e-commerce [73]. They differentiated between coordination and motivation costs. Their results suggest that process improvements and marketplace benefits were potentially large. Bartel et al. assembled a dataset on manufacturing plants in one narrowly defined industry (valve manufacturing) and analyzed several plant-level mechanisms through which IT could promote productivity growth [9]. Their results showed that: 1) plants that adopt new IT-enhanced equipment shifted their business strategies by producing more customized valve products; 2) IT investments improved the efficiency of all stages of the production process by reducing set-up times, run times and inspection times; and 3) adoption of new IT equipment coincided with increases in the skill requirements of machine operators, notably technical and problem-solving skills, and with the adoption of new human resource practices to support these skills.

Another emergent scientific field was Resource Based View (RBV) economics. The resource-based view of the firm attributes superior financial performance to organizational resources and capabilities [15, 44, 86, 117, 174]. For example, Kelley focused on a well-defined, easily recognizable process - precision metal-cutting - to conclude that there is a significant efficient advantage from using IT technologies [97]. Recently some scholars started investigating the value of individual IT Enterprise Systems (ESs) [84, 181]. An ES is a 
software application that provides services to a whole organization rather than a single department or group within it. For example, [181] provided first largescale evidence on the differential effects of ESs on corporate performance and provided new insights into the mediating role of innovation (see also Section 4).

\subsection{Framework requirements}

From the literature review, we can extract some requirements for our framework. A paradigmatic shift from orthodox economics to evolutionary economics seems to be imperative. The reasons are two-fold: 1) to provide a finer grain view of the intermediate processes between information networks and economic value (for example, in line with the work of [145]), instead of the prevailing use of direct statistical deterministic relations which provide few insights on how the actual value of information networks spreads across the economy; and 2) to provide a more convincing explanation of the causality issue. Furthermore, the framework should be able to cope both with analyses at the micro-level (e.g. [6]) as well at the macro-level (e.g. at the firm-level [25], at the industry-level [167] and at the country-level [96]). Multi-level theorists have drawn attention to the assumptions made for each level of analysis and how those assumptions can influence the entire range of theoretical and methodological issues associated to organizational studies [73]. Finally, the framework should be able to relate mechanistic views of the value of information networks in line with orthodox economics with more sociological views [74]. If this connection is indeed established, subsequent work should lay down theoretical and methodological propositions to connect different levels of analysis, from micro to macro-levels.

\section{Framework}

\subsection{Holon theory and evolutionary economics}

The term holon was introduced by Kostler in his book The Ghost in the Machine [98]. The word holon combines the Greek word for whole (holos with the suffix on which suggests particle or part. Thus, the holon is a part-whole, a nodal point in a nested hierarchy (referred to by Koestler as a holarchy). A holon can be described in terms of its holistic and independent nature, as well as partness and dependent nature [58]. Depending on the view point in a nested holarchical structure, the perception of what is the whole and part will change. The holon theory represents nested systems as organizations or economic systems by accounting for: 1) contrastive views of mechanistic physical and behavioral sciences, holistic system theories and sociological sciences; 2) evolutionary processes in social sciences; and 3) individual microlevel, as well as for the collective macro-level. 
The framework proposed by this article uses the concept of holon to refer to an entity that is part of and makes use of multi-level networks for exchange of information. The use of the holon theory in the context of information systems is not new, even at a technological level. Peters and Többen describe how the holon theory is applied in the Supply Chain Management (SCM) domain and how insights from there are achieved for higher efficiency and effectiveness [134]. Cheng et al. adopt the holon theory to develop a holonic information coordination system to support agile manufacturing activities [37]. Adelsberger proposes coordination mechanisms developed within economic frameworks to design manufacturing holonic multi agent systems [3]. Fischer describes a design of the architecture of a Computer Integrated Manufacturing (CIM) system based upon holonic models [67]. Brussel et al. discuss how a holonic reference architecture for manufacturing systems is crucial to achieve a high degree of self-similarity, which reduces the complexity to integrate new components and enables easy reconfiguration of the system [23].

As described before, evolutionary economics is concerned with the study of procedures or intermediate processes that transform an economy. In the particular case of the value of information networks, these procedures lead to interactions across holons with information as an input and value as an output. The notion that an economic system should be studied as a system of interactions and procedures is not new in some disciplines, particularly in sociological sciences [74]. In the literature on the value of IT [110], some authors already emphasize this notion of intermediate process. For example, Sambamurthy et al. argue that IT investments and capabilities influence firm performance through three significant organizational capabilities (agility, digital-options and entrepreneurial-alert) and strategic processes (capability-building, entrepreneurial action and co-evolutionary adaptation) [144]. The intermediate procedure in the work of Sambamurthy et al. is a capability. Eisenhardt and Martin referred to it as "the organizational and strategic routines by which firms achieve new resource configurations as markets emerge, collide, split, evolve, and die" [59]. Particularly referring to IT capabilities, Sambamurthy et al. defined IT competence as the organizational base of IT resources and capabilities and describes a firm's capacity for IT-based innovation by virtue of the available IT resources and the ability to convert IT assets and services into strategic applications" [144]. These IT capabilities are developed over time through a series of linked strategic decisions about investments in IT in parallel with development of organizational processes and knowledge [10]. Busetta et al. provide an agent-based formalization of capability and define capability as a cluster of plans, beliefs, events and scoping rules of them [31]. Prahalad and Hamel defined capability as "communication, involvement, and a deep commitment to working across organizational boundaries. It involves many levels of people and all functions" [138]. Helfat et al. mention that capability-based approaches continue to inform strategic management theory, because they acknowledge the importance of time and historicity in economic decision making by referring to organizational paths, they explain why every organizational entity is equipped with specific resources and an identity, they 
shed light on internal factors such as tacit knowledge, social complexity, organizational routines and competences [71, 83]. Other authors refer to capabilities as routines [47, 114,124$]$.

Independent of the label and definition, capabilities or routines are fundamentally processes that operate upon information. This article defines capabilities as procedures that an holon can utilize to navigate through information network flows that potentially bring value. The framework proposed by this article identifies a set of 13 capabilities. These are coordinatibility, cooperatibility, selectibility, biddability, adoptability, creatibility, brokerability, normatibility, trustability, culturability, decisability, modelability and perceptability. ${ }^{1}$ These concepts are simple and fundamental but are the underlying principles to really capture the value of information networks.

These capabilities were derived by investigating the large amount of literature on the value of digital information networks and searching for information networks' dependent processes. These processes were then related, abstracted from specific details, refined and finally conceptualized into the framework of capabilities. With this framework, we expect to provide a set of simple, fundamental but powerful concepts that can be used to combine research from more general and detailed, micro and macro studies (the capabilities apply both to the micro and macro levels). The definitions of the capabilities are mostly based upon previous work. The following step was to operationalize the capabilities, which refers to the process of linking the conceptual definitions to a specific set of measurement techniques or procedures [22].

Eurostat, the official organism from the European Union (EU) to collect statistical data, provides one of the richest data sources about the usage of IT [61]. The data spans the years 2002-2008, for various EU countries, with regional and sectoral breakdowns, for a large collection of different aspects related to the use of IT. This article uses the Eurostat data for two purposes: 1) to illustrate how the capabilities can be empirically measured, and therefore demonstrate the operational value of the framework; and 2) to provide a preliminary estimation of the relevancy of each capability. The relevancy of each capability is estimated with a linear regression between the operationalization for information networks (e.g. fraction of enterprises which have access to the Internet) and for an operationalization for the capability (e.g. fraction of enterprises using systems for managing production, logistics or service operations). Our operationalization intends to be exploratory to provide a basic ground for future extensions. Therefore, a linear regression is used for simplicity. In future work, other types of regression should be explored (for example, see Metcalfe's law [119]). The general linear regression function $y(x)$ consists of three parameters $\left(m, b, R^{2}\right)$. $m$ corresponds to the expected change of $y$ (associated with an operationalization for a capability) given a change in

\footnotetext{
${ }^{1}$ To identify the capabilities of the framework, we defined our own labels by mixing the action/verb/process specific to a capability (being aware that this is not always in line with the English language).
} 
$x$ (associated with an operationalization for information networks), thus, $m$ is the parameter that estimates the relevancy of the capability. $b$ represents the estimated average value of $y$ when $x$ is zero, thus, in this case it ideally should be zero. $R^{2}$ provides an estimation of the goodness of fit. $R^{2}$ is a fraction between 0 (meaning that $y$ and $x$ are unrelated) and 1 (meaning that $x$ allows to predict perfectly $y$ ) and has no units. Unfortunately, Eurostat does not collect enough IT usage variables to operationalize entirely the framework. Some capabilities are not measured at all (brokerability and culturability), others can not be measured distinguishably (decisability, modelability and perceptability) and others are measured in a limited way.

\subsection{Capabilities}

Coordination is a cross-disciplinary process. From the organizational perspective, the emphasis is on the investigation of coordination mechanisms increasing organizational performance. Based upon Malone and Crowston [113], we define coordinatibility as the capability of a holon to manage dependencies between organizational activities performed to achieve a goal. Within organizational management, coordination mechanisms are used in various applications, namely in systems of production, logistics and service operations. Figure 1 describes the relation between coordinatibility (operationalized by
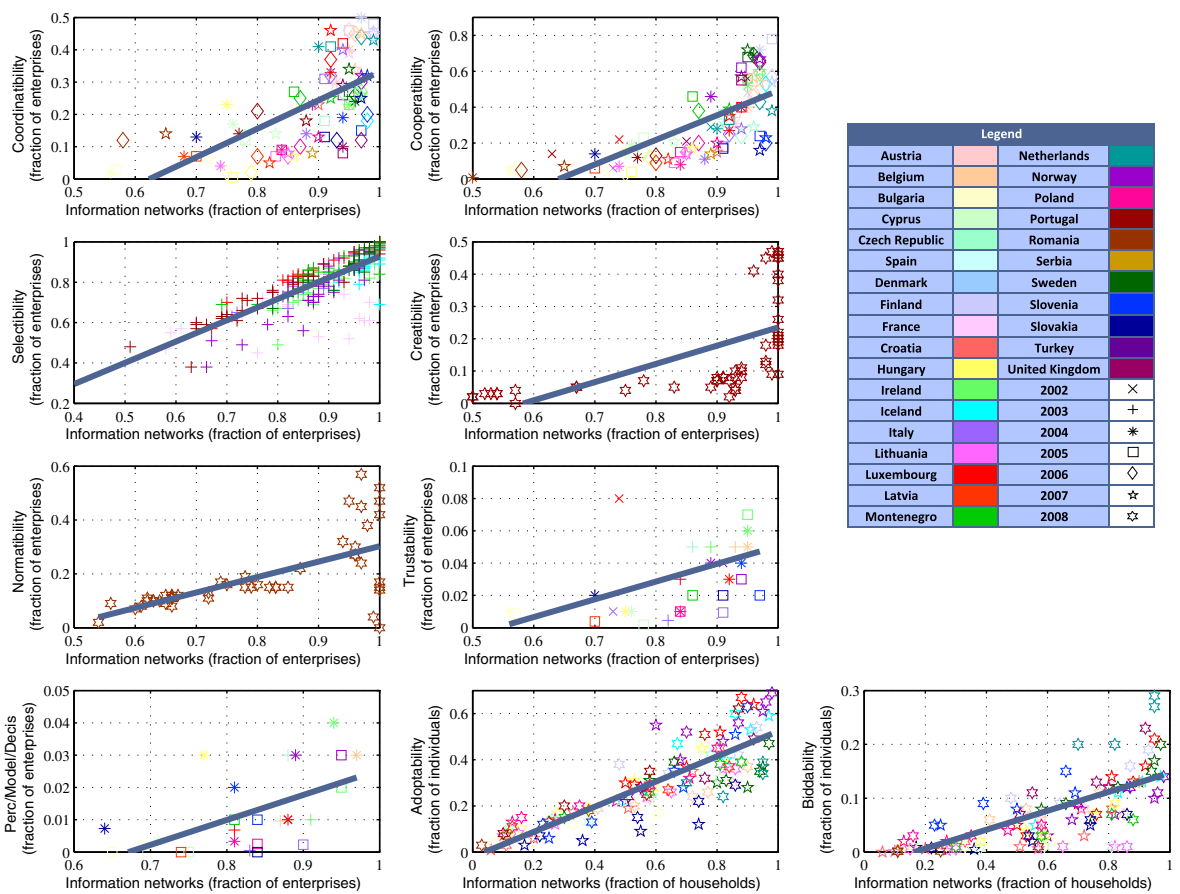

Fig. 1 Operationalization 
the fraction of enterprises using systems for managing production, logistics or service operations) and the fraction of enterprises which have access to the Internet (as an operationalization for information networks). Each data point in each graph is identified by a color (indicating the country) and a symbol (indicating the year). For clarity, sector and regional breakdowns are not identified. The parameters of the linear regression line are $(m=0.8806, b=$ $-0.5487, R^{2}=0.4323$ ).

Cooperation is achieved when a number of persons enters a relationship with others for a common benefit or collective action in pursuit of the common well-being [40]. Most often, cooperation is associated with coordination, but a few theorists clarify that they are distinct concepts [131]. Electronic commerce is just one example of cooperatibility which, based upon Consoli et al. [40] and Blecker [17], is defined as the capability of a holon to enter in a relationship with other holons for a common purpose. The deployment of information networks fuelled the rise of electronic commerce, matching the goals of buyers and sellers to cooperate in a supply and demand relation [175]. Figure 1 describes the relation between cooperatibility (operationalized by the fraction of enterprises that have ordered or received orders for products or services with the Internet) and the fraction of enterprises which have access to the Internet (as an operationalization for information networks). The parameters of the linear regression line are $\left(m=1.3696, b=-0.8778, R^{2}=0.5247\right)$.

Selection is another cross-disciplinary process. Yet, despite the pervasiveness of selection, Price points out that there has been no abstraction and generalization to obtain a general selection theory [139]. He predicts the appearance of such theory in the future, much as Shannon's communication theory appeared in the past. The World Wide Web (WWW) is an important source of information, and therefore, search engines are an essential WWW facility. Based upon Bulkley and Van Alstyne [27], we define selectibility as the capability of a holon to scan for the unknown or generate courses of action that improve on known alternatives. Over $80 \%$ of WWW searches use search engines to locate information [128]. Figure 1 describes the relation between selectibility (operationalized by the fraction of enterprises using Internet information search engines) and the fraction of enterprises which have access to the Internet (as an operationalization for information networks). The parameters of the linear regression line are $\left(m=1.0535, b=-0.1257, R^{2}=0.6850\right)$.

Through ages, bidding has been used to determine the value of hard-to-price items (e.g. antiques). Around $500 \mathrm{BC}$, bidding was used to auction off wives in ancient Babylon and the crown of a Roman emperor was sold by auctioning in 193 AD [35]. Objects, such as an art work, are typically awarded to the highest bid. A contract to build a highway constructions is usually given to the lowest bid. Gilbert investigates bidding on cable television franchises [75]. Shubik studies bidding in the dollar auction [152]. Smith studies bidding within animals [157]. We define biddability as the capability of a holon to influence other holons through proposals. Information networks have lowered the costs of organizing bidding auctions, which is leading to an increasing number of transactions [106]. Milgrom states that Internet transactions reduce the state 
space of the negotiation to the bid alone and has the "additional advantage of being an institution [Internet] where the conduct can be delegated to an unsupervised agent" [120]. Some developments enabled the development of online-bidding: security mechanisms, improved web browsers, increasing Internet usage, etc [12]. Figure 1 describes the relation between biddability (operationalized by the fraction of individuals using Internet for buying and selling goods) and the fraction of households which have access to the Internet (as an operationalization for information networks). The parameters of the linear regression line are $\left(m=0.1833, b=-0.0363, R^{2}=0.5136\right)$.

The capability of integrating knowledge in existing knowledge structures is a crucial step for success. In the current knowledge-based economies, growth is generated from innovation [14]. We define adoptability as the capability of a holon to acquire novel knowledge from other holons to be integrated in existing internal knowledge structures. Knowledge Management (KM) is the discipline concerned with the conceptualization of knowledge and the design of best-practices for the management of knowledge. Due to the nature of knowledge, it owes much to other disciplines, namely philosophy [136], psychology [76], social sciences [177], management sciences [148], computing, etc. Figure 1 describes the relation between adoptability (operationalized by the fraction of individuals that use Internet for training and education) and the fraction of households which have access to the Internet (as an operationalization for information networks). The parameters of the linear regression line are ( $\left.m=0.5446, b=-0.0212, R^{2}=0.7116\right)$.

As firms struggle in competitive environments, innovation becomes increasingly important. Information networks "renders the firm's capabilities amorphous in nature" [95] providing the ultimate potential for creation. Based upon Beesley and Cooper [14], we define creatibility as the capability of a holon to deliberately and purposely collate knowledge to generate new or novel ways to understand a particular phenomenon. Figure 1 describes the relation between creatibility (operationalized by the fraction of enterprises that consider Internet significant for the development of new products and services) and the fraction of enterprises which have access to the Internet (as an operationalization for information networks). The parameters of the linear regression line are $\left(m=0.5642, b=-0.3290, R^{2}=0.3162\right)$.

The combination of experiences, knowledge access, prominence and power creates inducements across actors, giving origin to information network structures [179]. Network opportunities enable an actor to create or restructure prior network structures (see Child's notion of strategic choice [38]). Network opportunities and the inertial constraints imposed by prior network structures themselves mutually reinforce and perpetuate information structures through a structuration process $[80,161]$. Hence, markets and organizations are networks of interdependent groups, in which information flows at higher speed within than across group boundaries [30]. Structural holes are network ties linking agents of separate network segments [29]. A bridging actor assumes the broker role, making a connection between different non-redundant information structures [72]. The brokerage capability across structural holes is an 
advantage for detecting and developing new ideas synthesized across disconnected pools of information. Based upon Burt [29], we define brokerability as the capability of a holon to act as a broker between unconnected individuals. Unfortunately, the Eurostat data does not allow us to empirically test this capability. However, in the existing literature, a vast number of theoretical and empirical studies can be found related with brokerability (e.g. [179]).

An agent's preferences might conflict with other agents' preferences. In such context, the importance of the concept of norms becomes apparent [50]. The development, enforcement, observation, violation, control and uphold of norms has been a topic of interest to several disciplines: philosophy, anthropology, history, sociology, political sciences, psychology, economy, law and even biology [137]. Based upon Horne [90], we define normatibility as the capability of a holon to share with other holons norms as rules with at least a certain degree of consensus which are enforceable by social sanctions. Figure 1 describes the relation between normatibility (operationalized by the fraction of enterprises that use agreed proprietary standards for automated data exchange) and the fraction of enterprises which have access to the Internet (as an operationalization for information networks). The parameters of the linear regression line are $\left(m=0.5730, b=-0.2703, R^{2}=0.4323\right)$.

Culture contains the rich fabric of religion, art, morals, customs and beliefs that diversify societies. Culture also manifests itself with tangible artefacts such as art and technology with visible and audible behaviour patterns as well as myths, images [64], heroes [164], rituals and ceremonies [135]. In the past, most sociologists viewed culture as a "seamless web" [165], unitary and internally coherent across groups and situations [20, 87]. In contrast, recent work depicts culture as fragmented across groups and inconsistent across its manifestations $[52,115]$. Culture emerges not in spite of optimizing motivations, but because of how those motivations are affected by incentives, cognitive constraints and institutional precedents [13]. Thus, cultural behaviour emerges from constrained self-interest. We define culturability as the capability of a holon to share with other holons general assumptions, values and patterns of behaviour emerging in time from their interaction. Managers use information networks to deliberately manipulate corporate culture. For example, Workflow Management Systems (WMS) strengthen organizational values (e.g. customer orientation) [53]. Unfortunately, the Eurostat data does not allow us to empirically test this capability. For an empirical example of the relevance of information networks upon culturability see [109].

Trust is an important lubricant of human relations (e.g. for friendship relations and economic transactions) [65]. Based upon Coleman [39], we define trustability as the capability of a holon to engage in a common effort with other holon before knowing how he will behave. The digital world replicates trust without much difference as the real world. Although the majority of the research done on trust in the Internet relates to electronic commerce, particularly authentication and security [101], various other examples of trust can be depicted. For example, in eBay, decisions about whether to trust sellers are made according to previous positive or negative comments from other buyers 
[16]. Figure 1 describes the relation between trustability (operationalized by the fraction of enterprises that see improving company image very important or of some importance as a motivation for Internet sales) and the fraction of enterprises which have access to the Internet (as an operationalization for information networks). The parameters of the linear regression line are $\left(m=0.1100, b=-0.0593, R^{2}=0.1401\right)$.

Executives of organizations are constantly facing decision-making situations. The traditional approach to decision-making emphasizes the effects that executives can have on strategic decisions. This approach has been labelled strategic-choice model [123]. Executives examine the firm's external environment and internal conditions and, using a set of objective criteria, decide upon the strategy [127]. The decision is benchmarked relatively to a standard [8]. An alternative perspective on decision-making argues that strategic decisions are mostly constrained by the external environment [142]. Independently of the importance given to the decision-maker relatively to the external environment, decision-making involves a series of sequential, rational and analytical processes [91] whereby a set of objective criteria are used to evaluate strategic alternatives [2, 33]. Based upon Camillus [33] and Ackoff [2], we define decisability as the capability of a holon to evaluate and decide among strategic alternatives. Empirical work was done upon the influence of information networks on decisability in, for example, impulse buying decisions [173].

Modeling is a widely used approach in problem solving. According to the basic ideas of Gestalt psychology [99], the human being tends automatically to minimize inconsistencies between novel input information in order to make sense of the world and to form consistent mental representations [77]. Consistency maximizing theories have also traditions in social psychology [153] with ample empirical evidence [176]. Modeling endows organisms to learn contingencies among events and actions, and therefore, it is a vital capability to adapt to dynamic environments [127]. Based upon Newell and Broder [127], we define modelability as the capability of a holon to understand the causeeffect structure of a system facilitating causal reasoning, categorization and induction. Modelability is investigated in the field of Artificial Intelligence (AI). With the introduction of connectionist theories and network models $[143,166]$, it became possible to extend modelability from simple dyadic or triadic constellations to more complex constellations of information [140]. Mental models are traditionally investigated within AI studies. Three examples of AI and information networks applications are [105]: 1) user modeling; 2) information integration; and 3) web-site management.

Both decisability and modelability are limited by the fact that biological organisms have limitations on how much information can be processed [121]. A possible way to incorporate the limitations of the mind into models of cognition is to propose simplified heuristics which enable organisms to make good enough judgements [132]. Such approaches develop frameworks considering the costs of thinking. Not only the limitations of the mind should be considered (e.g. memory and attention span), but also the ones imposed by the 
environment constrain the capability of perception (e.g. costs to achieve information) [154]. Stewart argues that the nature of cognition is strongly determined by its perceptual processes [162]. In particular, Stewart states "the external world can provide much of the connective tissue that integrates cognition". As an example, Stewart mentions the difficulty to make a proof in geometry without a diagram to inspect and mark. Traditional approaches to perception tend to deal with it in isolation from the processes of modeling and decision. However, due to their intricate and dependent nature, approaches have been proposed to integrate them emphasizing their interface [88]. Still, some authors based upon empirical evidences such as the direct parameter specification [125], value their conceptual separation. Neumann conceptualizes perception not as any activity of picking up information for the control of action, but as a specific kind of information pickup, which serves to establish and update an internal representation of the environment [126]. Based upon Neumann [126], we define perceptability as the capability of a holon to pickup information to establish and update internal representations of the environment. For example, when organizations implement new information systems, there is often a period of decreased performance [57].

Even conceptually speaking, it is a challenge to distinguish perceptability, modelability and decisability. However, for example, the literature on animal choice suggests that behavioural decisions can be made even by species with few or inexistent modeling and reasoning abilities [49]. Hence, we think it is appropriate to distinguish perceptability, modelability and decisability within a general capability of cognition. Empirically, capturing individually each of these capabilities is not possible with the data provided by the Eurostat surveys. However, in Fig. 1, we limitedly proxy these three capabilities all together (perc/model/decis) with the fraction of enterprises that see Internet sales as very important or of some importance to improve quality of services. The parameters of the linear regression line are $(m=0.0772, b=-0.0518$, $R^{2}=0.3290$ ).

\subsection{Resume}

Our framework, labeled Holonic Framework (HF), is resumed in Fig. 2. In the left side of the figure, a holarchy is represented. A holarchy refers to a hierarchical order of holons and a holon refers to a part-whole, a nodal point in a nested hierarchy [98]. A holon constitutes itself an open-ended multilevel hierarchical construction where each level of hierarchy is a network constructed by sub-wholes connected with each other within the same level [89], thus, a holon is a holarchy as well. Examples of holons and holarchies are biological organisms, organizations and economic sectors. The higher layers of a holarchy are more complex, flexible and unpredictable, while the lower layers are more mechanical, stereotype and predictable in their behaviour structures [134].

The links between holons represent flows of information. Holarchies and holons evolve towards increasingly complex structures with internal and 


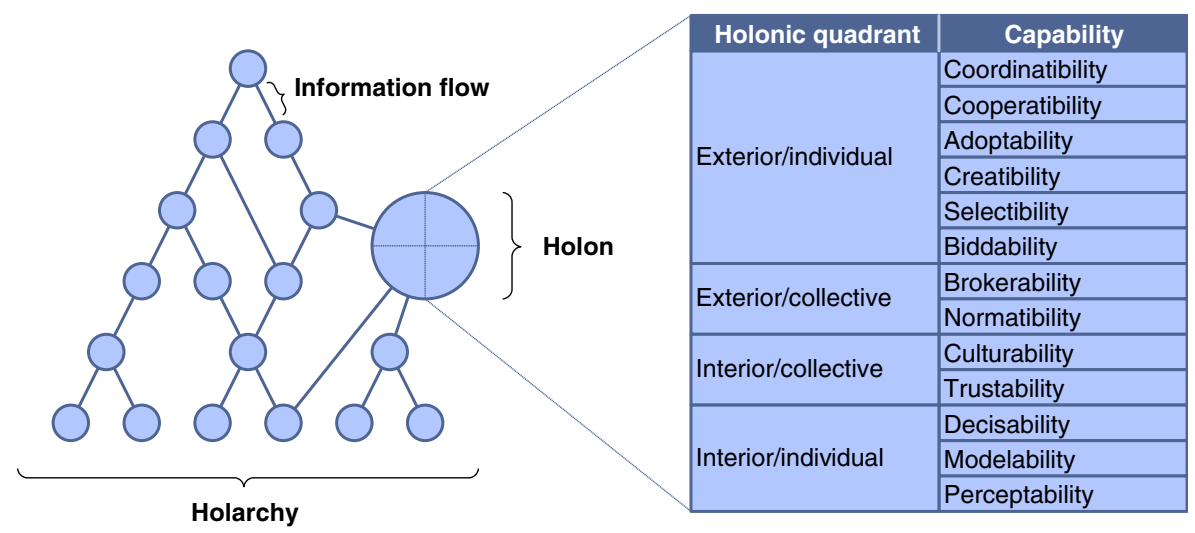

Fig. 2 Holonic Framework (HF)

external exchanges of information. Digital information networks enable the expansion and growth of information. In turn, such expansion and growth of information leads to organizational innovations which take increased advantage of information, feeding back again into new technological developments [21]. Thus, digital information networks reinforce the "self-propelling spiral of information" [94] towards increasingly complex holarchies. For instance, the proliferation and integration of a variety of information source databases change rather drastically the perception, sharing and delivery of financial services [147].

An important dualism in the definition of holon is the part-whole. Part is, by definition, something fragmented and incomplete, with no justification to exist by its own. On the other hand, whole implies something complete needing no further explanations. Peters and Többen relate partness of a holon to the tendency to integrate into a more comprising wholeness [134]. Wholeness is related by Peters and Többen to the stability of a holon provided by an internal canon of rules which define the possible actions and behaviours of the holon. In turn, these actions depend on observed environmental variables and are determined by a fundamental set of information processing capabilities. The framework proposed by this article defines capabilities as procedures that an holon can utilize to navigate through information network flows that potentially bring value. This article identifies 13 fundamental capabilities whose definitions are resumed in Fig. 3.

Any holonic process can be characterized according to two fundamental dimensions of existence: the interior-exterior (or objective-subjective) and the individual-collective dimensions [58]. The interior-exterior dimension refers to the relationship between the interior subjective world (e.g. intentions) and the exterior objective world (e.g. actions). The individual-collective dimension refers to the relationship between the individual self-steered world (e.g. goals) and the collective communital world (e.g. values). Hence, holonic processes can be framed in four quadrants (interior/individual, interior/collective, 


\begin{tabular}{|c|c|c|}
\hline Holonic quadrant & Capability & Definition \\
\hline \multirow{6}{*}{ Exterior/individual } & Coordinatibility & $\begin{array}{l}\text { Capability of a holon to manage dependencies between organizational activities } \\
\text { performed to achieve a goal }\end{array}$ \\
\hline & Cooperatibility & $\begin{array}{l}\text { Capability of a holon to enter in a relationship with other holons for a common } \\
\text { purpose }\end{array}$ \\
\hline & Adoptability & $\begin{array}{l}\text { Capability of a holon to acquire novel knowledge from other holons to be integrated } \\
\text { in existing internal knowledge structures }\end{array}$ \\
\hline & Creatibility & $\begin{array}{l}\text { Capability of a holon to deliberately and purposely collate knowledge to generate new } \\
\text { or novel ways to understand a particular phenomenon }\end{array}$ \\
\hline & Selectibility & $\begin{array}{l}\text { Capability of a holon to scan for the unknown or generate courses of action that } \\
\text { improve on known alternatives }\end{array}$ \\
\hline & Biddability & Capability of a holon to influence other holons through proposals \\
\hline \multirow[b]{2}{*}{ Exterior/collective } & Brokerability & Capability of a holon to act as a brocker between unconnected individuals \\
\hline & Normatibility & $\begin{array}{l}\text { Capability of a holon to share with other holons norms as rules with at least a certain } \\
\text { degree of consensus which are enforceable by social sanctions }\end{array}$ \\
\hline \multirow{2}{*}{ Interior/collective } & Culturability & $\begin{array}{l}\text { Capability of a holon to share with other holons general assumptions, values and } \\
\text { patterns of behavior emerging in time from their interaction }\end{array}$ \\
\hline & Trustability & $\begin{array}{l}\text { Capability of a holon to engage in a common effort with other holon before knowing } \\
\text { how he will behave }\end{array}$ \\
\hline \multirow{3}{*}{ Interior/individual } & Decisability & Capability of a holon to evaluate and decide among strategic alternatives \\
\hline & Modelability & $\begin{array}{l}\text { Capability of a holon to understand the cause effect structure of a system facilitating } \\
\text { causal reasoning, categorization and induction }\end{array}$ \\
\hline & Perceptability & $\begin{array}{l}\text { Capability of a holon to pickup information to establish and update internal } \\
\text { representations of the environment }\end{array}$ \\
\hline
\end{tabular}

Fig. 3 Definitions of the capabilities

exterior/individual, exterior/collective). Figure 3 frames the thirteen capabilities according to the interior/exterior and individual/collective dimensions.

\section{Discussion}

\subsection{Comparison with the DUT framework}

The Delft University of Technology (DUT) framework proposed by Zand and van Beers investigates the economic impact of ESs (see Fig. 4) [181]. The DUT framework considers five groups of ESs: Enterprise Resource Planning (ERP), Supply Chain Management (SCM), Customer Relationship Management (CRM), Knowledge Management System (KMS) and Document Management System (DMS). ESs enable innovation through new practices, routines, processes, methods, channels, services and/or products. The firm performance is evaluated using four metrics: growth, profitability, productivity and market share. Hence, the DUT framework identifies six intermediate processes between information networks and value: 1) ERP, 2) SCM, 3 ) CRM, 4) KMS, 5) DMS and 6) innovation. To compare our framework with the DUT framework we simply map the capabilities with the five groups of ES as well as innovation. The DUT framework also describes another component (firm, market and country-specific conditions) that, although not directly dependent on information networks, affects the performance of the firm.

ERP is an ES that is used to manage, coordinate and integrate all the resources, information, and functions of a business through shared data 


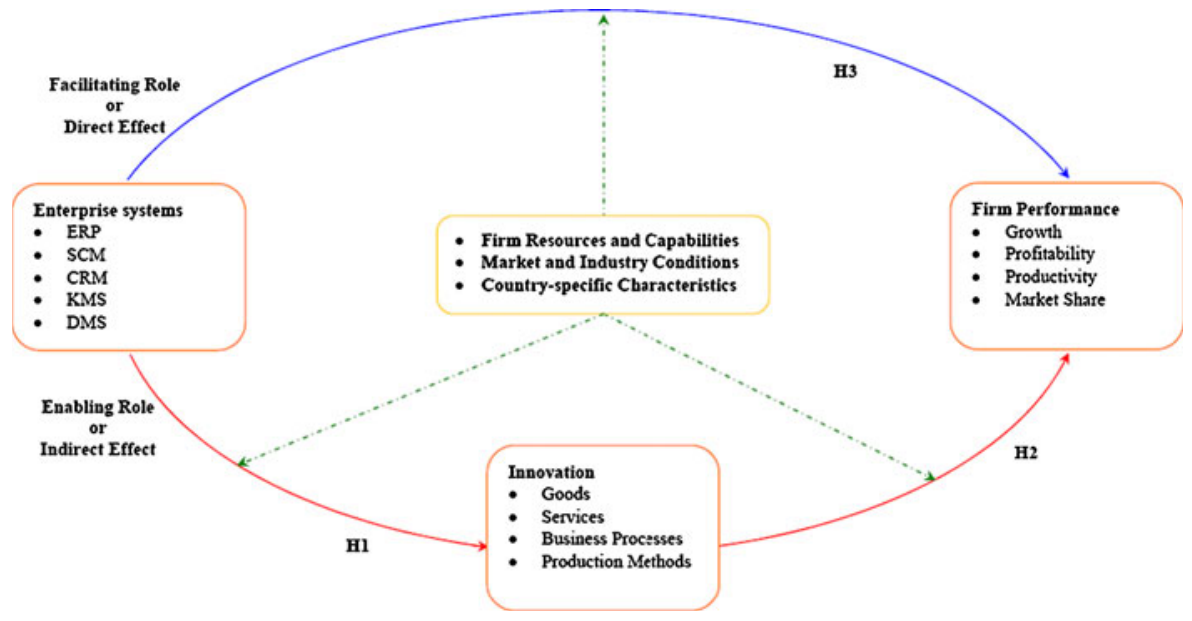

Fig. 4 The DUT reference framework. Figure retrieved from [181]

sources [60]. Thus, the central capability of an ERP is to coordinate information. Therefore, we map ERP with coordinatibility. Similarly to ERP, SCM is an ES that plans, coordinates and manages all the activities related to movement and storage of raw material, work-in-process inventory, and finished goods throughout the whole supply-chain of a company $[42,118]$. Hence, we also map SCM with coordinatibility. CRM is an ES that centrally tracks, records, organizes and processes the contacts of a company with its current or prospective customers [181]. Clearly, CRM should also be mapped to coordinatibility. Moreover, by supporting customer relationship management and strategy, CRM facilitates cooperation processes between firms and prospective customers. Thus, we map CRM also with cooperatibility. Finally, CRM also enables the establishment of trust ties between firms and customers [155]. Thus, we map CRM with trustability. KMS is an ES to collect, organize, process, share and manage the information and knowledge assets of an organization [5]. Thus, the central feature of KMS is to facilitate the adoption of knowledge, and therefore, we map it to adoptability. DMS is an ES to collaboratively create, edit, review, index, track, search, retrieve, publish and archive electronic documents and digitalized images of article documents [181]. The main feature of DMS is to support the creation of documents. Hence, we map it with creatibility. The final concept, innovation, is associated by the authors both to adoptability, in the sense of imitation of knowledge, and creatibility, in the sense of supporting the creation of new ideas. Thus, we map the DUT concept of innovation both with adoptability and creatibility.

ERP, SCM and CRM are all mapped with coordinatibility. KMS and innovation with adoptability. DMS and innovation with creatibility. Hence, the DUT framework fails to identify ESs associated with eight capabilities: biddability, selectibility, brokerability, normatibility, culturability, decisability, modelability and perceptability. Given the empirical character intended in the 
work of Zand and van Beers, it is not strange that the DUT framework fails to identify some of the intermediate processes between information networks and economic value. The empirical objects chosen, ESs, are technologies for which is easy to verify the availability. Thus, the work of Zand and van Beers is still much in line with the orthodox economic approach. Doing so, it fails to identify the processes with a more intangible (e.g. culturability), perhaps less significant (biddability) or underlying nature (selectibility).

\subsection{Empirical validation}

In the state of the art, we discussed how differently the concept of causality is seen in the orthodox and in the evolutionary economic approaches. In orthodox economics, causality is simply left apart or it is given a deterministic interpretation. In evolutionary economics, causality stands upon finer grain procedural descriptions of causal paths in a much more realistic and sophisticated view of reality. The different view upon causality in orthodox and evolutionary economics raises a fundamental difference of what is referred to as empirical validation.

The performance of an economic entity is, in general, dependent on external factors. For example, market concentration, competitive technology or regulatory regime. Naturally, these external factors also influence the value that a firm obtains from information networks. Thus, the value of information networks can be said to depend on direct factors (e.g. the capabilities) and indirect (or external) factors.

Following their view of causality, orthodox economists empirical validation is performed by investigating relations between variables using differential equations, regression or related techniques [158]. For example, orthodox economists would observe information networks measuring the penetration rate, the economic value by measuring productivity and their relation using a regression technique. These observations are necessarily very aggregated, and therefore, rough. One might get what in organizational theory is called a garbage can model and in software engineering a garbage in garbage out problem. Moreover, such an empirical validation approach provides few insights on the phenomenon under study. Finally, lack of readily available (only those concepts are included for which data is available) or frequently noisy data (for example, due to the influence of external factors) might hamper the progress of research.

Following their view of causality, evolutionary economists' empirical validation is identified with a consistent covariation between two variables (see the quasi-experimentation design of [41]). Thus, their concern is not to observe and correlate aggregated variables of information networks and economic value, but to identify stylized facts that reveal the intermediate multi-level processes (the capabilities). This form of empirical validation provides a much deeper understanding of the phenomenon, but fails to provide a statistical explanation of regularities across very aggregated variables (and, thus, also to account for the external factors). If indeed evolutionary economists proceed to the 
orthodox view of empirical validation, then many challenges raise [62]: how to relate and calibrate parameters, initial conditions and stochastic variability to existing empirical data? To what extent can we truly compare empirical data with stylized facts or, alternatively, with counter-factuals? And many other aspects.

\subsection{Comparison with the MIT framework}

The MIT framework proposed by Bulkley and Van Alstyne [27] presents a set of seventeen hypotheses in an effort to connect information (in general) with productivity (see Fig. 5). To compare our framework with the MIT framework, we map the hypotheses with the capabilities described in our framework. Six MIT framework hypotheses are directly and uniquely mapped with six capabilities: 1) H1 $\leftrightarrow$ coordinatibility; 2) $\mathrm{H} 2 \leftrightarrow$ selectibility; 3) $\mathrm{H} 3 \leftrightarrow$ adoptability; 4) $\mathrm{H} 4 \leftrightarrow$ creatibility; 5) $\mathrm{H} 5 \leftrightarrow$ brokerability; and 6) H6 $\leftrightarrow$ modelability. Three MIT hypotheses are mapped with normatibility. These are: 1) H7; 2) H8 (norms/standards); and 3) H9 (modular design as a organizational norm for

\begin{tabular}{|c|c|c|}
\hline & Hypothesis & Capability \\
\hline H1 & $\begin{array}{l}\text { Coordinating information improves the efficiency of existing processes by reducing the number of bad handoffs and } \\
\text { improving resource utilization rates. }\end{array}$ & Coordinatibility \\
\hline $\mathrm{H} 2$ & $\begin{array}{l}\text { Efficient information search relies on structuring a solution to provide a balanced index, sorting choices to provide best } \\
\text { option first, and stopping when the net expected value of the best unsampled choice no longer exceeds the best sampled } \\
\text { choice. }\end{array}$ & Selectibility \\
\hline H3 & Optimal sharing occurs between partners with partial information overlap. & Adoptability \\
\hline H4 & $\begin{array}{l}\text { Know how can increase productivity by creating new options for those who are unfamiliar with it. This includes options for } \\
\text { recursively creating new process know how. Sharing disseminates these options. }\end{array}$ & Creatibility \\
\hline H5 & Information sharing reduces balkanization, increasing productivity by promoting economies of scope and scale. & Brokerability \\
\hline H6 & $\begin{array}{l}\text { Simulation and modeling help decision makers more accurately identify leverage points within dynamic systems and } \\
\text { reduce the cost of exploring alternative courses of action. They boost productivity by reducing wasted resources and } \\
\text { creating new options. }\end{array}$ & Modelability \\
\hline H7 & $\begin{array}{l}\text { Absolute incentives encourage information sharing, which promotes group productivity; relative incentives discourage } \\
\text { information sharing, but promote individual productivity. The optimal incentive policy interms of productivity becomes } \\
\text { increasingly absolute with increasing task interdependence. }\end{array}$ & Normatibility \\
\hline H8 & $\begin{array}{l}\text { Information routines and standards reduce complexity. They foster interoperability and sharing, but limit adaptation and } \\
\text { flexibility.Optimal information standardization increases with decision stability. }\end{array}$ & Normatibility \\
\hline H9 & $\begin{array}{l}\text { Modular design scan increase productivity by spreading the risk of process failure or enabling new combinations of } \\
\text { process that extend the efficient frontier. }\end{array}$ & Normatibility \\
\hline H10 & $\begin{array}{l}\text { Centralized decisions promote decision consistency, global perspective, and avoid wasteful duplications. Decentralized } \\
\text { decisionspromote data gathering, distributed incentives and adaptation. Productivity increasesto the extent that } \\
\text { distributing control optimally balances these factors in light of complementarity and indispensability. }\end{array}$ & Decisability \\
\hline H11 & More precise information improves decisions by reducing waste. & Decisability \\
\hline H12 & $\begin{array}{l}\text { Information push benefits individuals and organizations that control undervalued assets(owners of overvalued assets } \\
\text { incur loses). Efficiency increaseswhen resource allocations rebalance to account for problems and opportunities. }\end{array}$ & Decisability \\
\hline H13 & $\begin{array}{l}\text { The need for redundant links to critical information sourcesincreaseswith the likelihood of agent incapacitation. Latent } \\
\text { links are needed for occasions when novel domain specific experience becomes essential. Redundant links conflict with } \\
\text { the desire to use these links for new information. }\end{array}$ & Perceptability \\
\hline H14 & Optimal information gathering balancesthe costs of overload against the costs of ignorance. & Perceptability \\
\hline H15 & $\begin{array}{l}\text { Network efficiency balancesnetwork size and diversity of contacts. Network effectiveness distinguishes primary from } \\
\text { secondary contacts and focuses resources on preserving primary contacts. Individuals who are more central will be more } \\
\text { effective. }\end{array}$ & \\
\hline H16 & $\begin{array}{l}\text { Information that reduces risk aversion increases productivity when it leads to actions that are closer to true risk neutral } \\
\text { levels. }\end{array}$ & \\
\hline 117 & rmation gathering and flow increases with the rate of environmental change. & \\
\hline
\end{tabular}

Fig. 5 Mapping with the MIT framework 
production). Three MIT hypotheses are mapped with decisability. These are: 1) $\mathrm{H} 10$; 2) $\mathrm{H} 11$; and 3) $\mathrm{H} 12$ (the intermediate process is information push, thus, a decision process made by the holon in face of an external factor: undervalued assets). Two MIT hypotheses are mapped with perceptability. These are: 1) H13; and 2) H14.

One MIT framework hypothesis (H15) describes the value of information based upon network topological metrics (size, variety and centrality of the holon relatively to the network). Thus, it can be applied to any intermediate process that generates networks (e.g. social and cultural networks). This hypothesis is not helpful to identify any underlying microscopic intermediate process, and therefore, we do not map it to any capability. Two other MIT hypotheses are also not mapped to our framework, because they relate to external indirect factors (environment change and risk) that, although indirectly affecting the productivity of an organization, are not necessarily intermediate processes between information and productivity. These are: 1) H16 (environment risk); and 2) H17 (environment change).

Four capabilities (biddability, cooperatibility, trustability and culturability) are not addressed by the MIT framework. Contrary to our pure evolutionary approach, the MIT framework, partially, still follows the orthodox economic approach in the sense that there is a brief description of the intermediate process accompanied with explicit references to end-to-end observables. For example, in the hypothesis $\mathrm{H} 4$, the mediating process is briefly addressed (creatibility), the input observable is "know-how" and the output observable is "productivity". In our definition of creatibility, we elaborate rather upon the intermediate process: creatibility is the capability of a holon to deliberately and purposely collate knowledge to generate new or novel ways to understand a particular phenomenon. An important implication results from focusing in the intermediate processes without specifying the end-to-end observables: a variety of other applications becomes obvious. In parallel with value assessment, we are investigating two other applications for our framework: service design [112] and infrastructure interoperability [111]. But even within value assessment, the evolutionary holonic approach brings a significant difference to the concept of value than the one understood by the MIT and the DUT frameworks.

\subsection{Value from the evolutionary perspective}

In earlier times, value in the economy lay on the supply side. For example, Richard Cantillon (1680-1734) in his Land Theory of Value [82], believed that value depends on how much scarce land was used in making a product, and Karl Marx saw labour as the ultimate supply of value [116]. Then, mainly with the work of Stanley Jevons (1835-1882) [92] and the proposition that value is determined by consumers' utility, the origin of value moved to the demand side. Finally, in the neoclassical synthesis, the supply side meets the demand side: scarce factors of production meets individual consumer utilities through market mechanisms [172]. Orthodox economic views of value are still 
predominant today. For example, in the MIT and the DUT frameworks, value is the productivity of an organization (value in the supply side).

Foster states: "economics, like all the sciences, builds on propositions concerning thermodynamics and, therefore, such propositions appear to be the correct starting point in developing analytical frameworks within which economic processes can be understood" [69]. Energy feeds the process of evolutionary value creation following the second law of thermodynamics [7]. Without processing information, "systems can not retain successful patterns of energy flow that enhance their ability to maintain order" [28]. Thus, from an evolutionary perspective, information is the origin of value. This view does not contradict orthodox economics. For example, Robert Solow saw knowledge as the origin of value [159], but intermediate information processes were treated as mysterious and accountable only by rough observables of value (e.g. productivity). By providing procedural descriptions of information processing intermediate processes, evolutionary economics puts information in the heart of value creation. Hence, more sophisticated measures for value become available, in comparison with the measures used in orthodox economics. Hence, our framework presents a fundamental difference in comparison with previous work (namely, the MIT and the DUT frameworks). Instead of accounting information with indirect inputs (e.g. productivity) in value creation, our framework specifies explicitly the intermediate processes by which information network flows can be processed and (evolutionary) value generated (economic or other).

\section{Conclusions}

The main contribution of this article is a framework, labeled Holonic Framework (HF), that accounts for the value of digital information networks. We demonstrated that our framework provides significant conceptual addedvalue by comparing it with two state of the art reference frameworks (the DUT framework fails to identify eight capabilities and the MIT framework fails to identify four capabilities). Due to the theoretical ground upon which it was developed, we argued that our framework is able to capture the value of information networks, not only from the orthodox economic perspectives accounted both in the DUT (growth, profitability, productivity and market share) and the MIT framework (productivity), but also from any other perspective of value (e.g. social or environmental). We demonstrated that our framework has a much wider application range than the DUT and MIT frameworks. For example: 1) to make the development of information networksupported services more systematic [112]; 2) to investigate levels of economic cross-sectoral IT infrastructure interoperability [111]; and 3) to be used by Eurostat to redesign their surveys in a more conceptually valid way.

The HF has two important limitations which can be the motivation for future work. The first lies in the level of formalization of the capabilities. 
The definitions of the capabilities was mostly based upon previous multiple and independently developed work. However, capabilities are essentially information processes, and therefore their definitions should be derived from a unique and fundamental theory of information. The quest for such theory is in process. Umpleby states: "matter and energy have been subject of scientific investigation for several hundred years, a scientific conception of information is relatively new" [170]. Bateson defines information as that which changes us or the difference that makes a difference [11]. Kallinikos states that information is self-referential and non-foundational [94]. Shannon defined information as a reduction of uncertainty [149]. Adriaans addresses the idea of meaningful information [4]. Buckland defined information-as-thing, information-asknowledge and information-as-process [26]. While mathematical formulations are recurrent in traditional physics, it is questionable if mathematical formulations are possible in information related problems. Most of the research in social sciences still uses purely verbal representation of social phenomena [130] which has the downside of making it harder to investigate causal relations going from assumptions to implications and scientific knowledge to build up. With the advent of powerful and accessible simulation computational tools, more formal representation is emerging for social phenomena making the assessment of consistency, generalization and other desirable properties easier.

The second important limitation relates to the operationalization of the framework. Although this article was based upon one of the best sources of empirical data on the value of IT, the Eurostat's surveys on ICT used by households and enterprises, the operationalization of the capabilities can be significantly improved. Some of the capabilities were impossible to operationalize (brokerability and culturability) and others were operationalized in a limited way. The validity of the measurements, referring to how well the conceptual and operational definitions mesh with each other, should be improved. Furthermore, reliability tests should also be performed to demonstrate that the numerical results produced by an indicator do not vary because of the characteristics of the measurement method. A more formal conceptualization of the capabilities, a more precise level of measurements, use of multiple indicators and use of various test-pilots would improve the operationalization of the framework. Looking into other data sources is an obvious way to proceed (e.g. the United Nations (UN) Statistical Commission has precise guidelines on how to measure ICT related aspects).

Acknowledgements We thank the Royal Dutch KPN, TNO and the Delft University of Technology for funding this research within the Trans-sector Research Academy for complex Networks and Services (TRANS) initiative. Furthermore, we would like to thank two anonymous reviewers for their comments which contributed to improve this article.

Open Access This article is distributed under the terms of the Creative Commons Attribution Noncommercial License which permits any noncommercial use, distribution, and reproduction in any medium, provided the original author(s) and source are credited. 


\section{References}

1. ACIL Tasman (2004). Economic impacts of broadband adoption in Victoria. Technical report, ACIL Tasman.

2. Ackoff, R. (1981). On the use of models in corporate planning. Strategic Management Journal, 2(4), 353-359.

3. Adelsberger, H. (2000). Economic coordination mechanisms for holonic multi-agent systems. In DEXA '00: Proceedings of the 11th international workshop on database and expert systems applications (p. 236). IEEE Computer Society.

4. Adriaans, P. (2009). Between order and chaos: The quest for meaningful information. Theory of Computing Systems, 45(4), 650-674.

5. Alavi, M., \& Leidner, D. (2001). Review: Knowledge management and knowledge management systems: Conceptual foundations and research issues. MIS Quarterly, 25(1), 107136.

6. Aral, S., Brynjolfsson, R., \& Van Alstyne, M. (2008). Information, technology and information worker productivity: task level evidence. Working Paper Series, Social Science Research Network.

7. Atkins, P. (1984). The second law. New York: Scientific American Library.

8. Baron, J. (2004). Normative models of judgment and decision making. In Blackwell handbook of judgment and decision making (pp. 19-36). Blackwell Publishing.

9. Bartel, A., Ichniowski, C., \& Shaw, K. (2007). How does information technology affect productivity? Plant-Level comparisons of product innovation, process improvement, and worker skills. The Quarterly Journal of Economics, 122(4), 1721-1758.

10. Barua, A., \& Mukhopadhyay, T. (2000). Information technology and business performance: Past, present, and future. In Framing the domains of IT management: Projecting the future through the past (pp. 65-84). Pinnaflex Education Resources, Cincinnati, OH.

11. Bateson, G. (1972). Steps to an ecology of mind. New York: Ballantine Books.

12. Beam, C., \& Segev, A. (1998). Auctions on the internet: A field study. CITM Working Paper 98-WP-1032, Haas School of Business, University of California at Berkeley, Berkeley.

13. Bednar, J., \& Page, S. (2007). Can game(s) theory explain culture? The emergence of cultural behavior within multiple games. Rationality and Society, 19(1), 65-97.

14. Beesley, L., \& Cooper, C. (2008). Defining knowledge management (KM) activities: Towards consensus. Journal of Knowledge Management, 12(3), 48-62.

15. Bharadwaj, A. (2000). A resource-based perspective on information technology capability and firm performance: An empirical investigation. MIS Quarterly, 24(1), 169-196.

16. Bhattacharjee, R., \& Goel, A. (2005). Avoiding ballot stuffing in eBay-like reputation systems. In P2PECON '05: Proceedings of the 2005 ACM SIGCOMM workshop on economics of Peer-to-Peer systems (pp. 133-137). ACM.

17. Blecker, T. (2003). Towards an production concept based on internet technologies. In Proceedings of the 6th international conference on industrial engineering and production management-IEPM'03 (Vol. 3, pp. 139-149).

18. Borges, A. (1986). Applied general equilibrium models: An assessment of their usefulness for policy analysis. Technical Report 7, Organisation for Economic Co-operation and Development.

19. Borgman, A. (1999). Holding on to reality: The nature of information at the turn of the millennium. The University of Chicago Press.

20. Bourdieu, P. (1984). Structures, habitus, practices. Stanford University Press.

21. Bouwman, H., van den Hooff, B., van de Wijngaert, L., \& van Dijk, J. (2005). Information and communication technology in organizations: Adoption, implementation, use and effects. Sage Publications.

22. Bridgman, P. (1927). The logic of modern physics. The Macmillan Company.

23. Brussel, H. V., Wyns, J., Valckenaers, P., Bongaerts, L., \& Peeters, P. (1998). Reference architecture for holonic manufacturing systems: PROSA. Computers in Industry, 37(3), 255-274.

24. Brynjolfsson, E., \& Hitt, L. (1996) Paradox lost? Firm-level evidence on the returns to information systems spending. Management Science, 42(4), 541-558. 
25. Brynjolfsson, E., \& Hitt, L. (2000). Beyond computation: Information technology, organizational transformation and business performance. Journal of Economic Perspectives, 14(4), 23-48.

26. Buckland, M. (1991). Information as thing. Journal of the American Society for Information Science, 42(5), 351-360.

27. Bulkley, N., \& Van Alstyne, M. (2004). Why information should influence productivity. Working Paper Series 202, MIT Sloan School of Management.

28. Burgin, M., \& Simon, I. (2009). Information, energy, and evolution. http://cogprints.org/2359/.

29. Burt, R. (1992). Structural holes, the social structure of competition. Harvard University Press.

30. Burt, R. (2000). The network structure of social capital. Research in Organizational Behaviour, 22, 345-423.

31. Busetta, P., Howden, N., Rönnquist, R., \& Hodgson, A. (2000). Structuring BDI agents in functional clusters. In ATAL '99: 6th international workshop on intelligent agents VI, agent theories, architectures, and languages (ATAL) (pp. 277-289). Springer-Verlag.

32. Byrd, T., \& Marshall, T. (1997). Relating information technology investment to organizational performance: A causal model analysis. Omega, 25(1), 43-56.

33. Camillus, J. (1982). Reconciling logical incrementalism and synoptic formalism-an integrated approach to designing strategic planning processes. Strategic Management Journal, 3(3), 277-283.

34. Carr, N. (2003). IT doesn't matter. Harvard Business Review (pp.41-49).

35. Cassady, R. (1967). Auctions and auctioneering. University of California Press.

36. CEBR (2003). The economic impact of a competitive market for broadband. Technical Report, The Broadband Industry Group.

37. Cheng, F., Yang, H., \& Lin, J. (2004). Development of holonic information coordination systems with failure-recovery considerations. IEEE Transactions on Automation Science and Engineering, 1(1), 58-72.

38. Child, J. (1972). Organizational structure, environment and performance: The role of strategic choice. Sociology, 6(1), 1-22.

39. Coleman, J. (1990). Foundations of social theory. The Belknap Press of Harvard University Press.

40. Consoli, A., Tweedale, J., \& Jain, L. (2006). The link between agent coordination and cooperation. In Z. Shi, K. Shimohara, \& D. Feng (Eds.), IFIP international federation for information processing. Intelligent information processing III (Vol. 228) Boston: Springer.

41. Cook, T., \& Campbell, D. (1979). Quasi-experimentation: Design and analysis issues for field settings. Wadsworth Publishing.

42. Cooper, M., Lambert, D., \& Pagh, J. (1997). Supply chain management: More than a new name for logistics. The International Journal of Logistics Management, 8(1), 1-14.

43. Correa, L. (2006). The economic impact of telecommunications diffusion on UK productivity growth. Information Economics and Policy, 18(4), 385-404.

44. Corso, M., \& Paolucci, E. (2001). Fostering innovation and knowledge transfer in product development through information technology. International Journal of Technology Management, 22, 126-148.

45. Crandall, R., Lehr, W., \& Litan, R. (2007). The effects of broadband deployment on ontput and employment: A cross-sectional analysis of U.S. data. Brookings Institution Press.

46. Cronin, F., Parker, E., Colleran, E., \& Gold, M. (1991). Telecommunications infrastructure and economic growth: An analysis of causality. Telecommunications Policy, 15(6), 529-535.

47. Cyert, R., \& March, J. (1963). A behavioural theory of the firm. Blackwell Publishers.

48. Datta, A., \& Agarwal, S. (2004). Telecommunications and economic growth: A panel data approach. Applied Economics, 36(15), 1649-1654.

49. Davis, S., \& Bostrom, R. (1993). Training end users: An experimental investigation of the Roles of the computer interface and training methods. MIS Quarterly, 17(1), 61-85.

50. Dignum, F., Meyer, J., Wieringa, R., \& Kuiper, R. (1996). A modal approach to intentions, commitments and obligations: Intention plus commitment yields obligation. In Deontic logic, agency and normative systems (pp. 80-97). Springer-Verlag.

51. Dijk, M. V., \& Mulder, M. (2005). Regulation of telecommunication and deployment of broadband. CPB Memoranda 131, CPB Netherlands Bureau for Economic Policy Analysis.

52. Dimaggio, P. (1997). Culture and cognition. Annual Review of Sociology, 23, 263-287. 
53. Doherty, N., \& Perry, I. (2001). The cultural impact of workflow management systems in the financial services sector. The Service Industries Journal, 21, 147-166.

54. Dopfer, K. (1986). Causality and consciousness in economics: Concepts of change in orthodox and heterodox economics. Journal of Economic Issues, 20(2), 509-523.

55. Dopfer, K. (2004). The economic agent as rule maker and rule user: Homo Sapiens oeconomicus. Journal of Evolutionary Economics, 14(2), 177-195.

56. Duggal, V., Saltzman, C., \& Klein, L. (2007). Infrastructure and productivity: An extension to private infrastructure and it productivity. Journal of Econometrics, 140(2), 485-502.

57. Edmonson, A., Winsolow, A., Bohmer, R., \& Pisano, G. (2003). Learning how and learning what: Effects of tacit and codified knowledge on performance improvement following technology adoption. Decision Sciences, 34(2), 197-223.

58. Edwards, M. (2005). The integral holon: A holonomic approach to organisational change and transformation. Journal of Organizational Change Management, 18(3), 269-288.

59. Eisenhardt, K., \& Martin, J. (2000). Dynamic capabilities: What are they? Strategic Management Journal, 21(10/11), 1105-1111.

60. Esteves, J., \& Pastor, J. (2001). Enterprise resource planning systems research: An annotated bibliography. Communications of the AIS, 7(8), 2-54.

61. Eurostat (2010). ICT usage and e-Commerce. http://epp.eurostat.ec.europa.eu/portal/page/ portal/information_society/introduction. Accessed 22 November 2010.

62. Fagiolo, G., Moneta, A., \& Windrum, P. (2007). A critical guide to empirical validation of agent-based models in economics: Methodologies, procedures, and open problems. Computational Economics, 30(3), 195-226.

63. Farmer, J., \& Foley, D. (2009). The economy needs agent-based modelling. Nature, 460(6), 685-686.

64. Farr, R., \& Moscovici, S. (1984). Social representations. Cambridge University Press.

65. Fehr, E. (2009). On the economics and biology of trust. Journal of the European Economic Association, 7(2-3), 235-266.

66. Firth, L., \& Mellor, D. (2005). Broadband: Benefits and problems. Telecommunications Policy, 29(2-3), 223-236.

67. Fischer, K. (1999). Agent-based design of holonic manufacturing systems. Robotics and Autonomous Systems, 27(1), 3-13.

68. Ford, G., \& Koutsky, T. (2005) Broadband and economic development: A municipal case study from Florida. Applied Economic Studies, 17(3), 216-229.

69. Foster, J. (1997). The analytical foundations of evolutionary economics: From biological analogy to economic self-organization. Structural Change and Economic Dynamics, 8(4), 427-451.

70. Freeman, C., \& Louca, F. (2001). As time goes by: From the industrial revolutions to the information revolution. Oxford University Press.

71. Freiling, J., Gersch, M., \& Goeke, C. (2008). On the path towards a competence-based theory of the firm. Organization Studies, 29(8-9), 1143-1164.

72. Fritsch, M., \& Kauffeld-Monz, M. (2008). The impact of network structure on knowledge transfer: An application of social network analysis in the context of regional innovation networks. The Annals of Regional Science, 44(1), 21-38.

73. Garicano, L., \& Kaplan, S. (2001). The effects of business-to-business e-Commerce on transaction costs. Journal of Industrial Economics, 49(4), 463-85.

74. Giddens, A. (1993). New rules of sociological method: A positive critique of interpretative sociologies. Stanford University Press.

75. Gilbert, R. (1977). Valuation uncertainty and competitive bidding. Technical Report, University of California at Berkeley. Unpublished manuscript.

76. Glaser, R. (1984). Education and thinking: The role of knowledge. American Psychologist, 39(2), 93-104.

77. Glockner, A., \& Betsch, T. (2008). Modelling option and strategy choices with connectionist networks: Towards an integrative model of automatic and deliberate decision making. Judgment and Decision Making, 3(3), 215-228.

78. Greenstein, S., \& McDevitt, R. (2009). The broadband bonus: Accounting for broadband internet's impact on U.S. GDP. NBER Working Papers 14758, National Bureau of Economic Research, Inc. 
79. Greenstein, S., \& Spiller, P. (1995). Modern telecommunications infrastructure and economic activity: An empirical investigation. Industrial and Corporate Change, 4(4), 647-665.

80. Gulati, R., \& Gargiulo, M. (1999). Where do interorganizational networks come from? The American Journal of Sociology, 104(5), 1439-1493.

81. Hardy, A. (1980). The role of the telephone in economic development. Telecommunications Policy, 4(4), 278-286.

82. Hayek, F. (1985). Richard Cantillon. Journal of Libertarian Studies, 7(2), 217-247.

83. Helfat, C., Finkelstein, S., Mitchell, W., Peteraf, M., Singh, H., Teece, D., et al. (2007). Dynamic capabilities: Understanding strategic change in organizations. Wiley-Blackwell.

84. Hendricks, K., Singhal, V., \& Stratman, J. (2007). The impact of enterprise systems on corporate performance: A study of ERP, SCM, and CRM system implementations. Journal of Operations Management, 25, 65-82.

85. Hitt, L., \& Brynjolfsson, E. (1996). Productivity, business profitability, and consumer surplus: Three different measures of information technology value. MIS Quarterly, 20(2), 121-142.

86. Hitt, L., Wu, D., \& Zhou, X. (2002). Investment in enterprise resource planning: Business impact and productivity measures. Journal of Management Information Systems, 19(1), 7198.

87. Hofstede, G. (1980). Culture's consequences: International differences in work-related values. Beverly Hills: Sage.

88. Hommel, B., Musseler, J., Aschersleben, G., \& Prinz, W. (2001). The theory of event coding (TEC): A framework for perception and action planning. Behavioral and Brain Sciences, 24(5), 849-878.

89. Honma, N., Abe, K., Sato, M., \& Takeda, H. (1998). Adaptive evolution of holon networks by an autonomous decentralized method. Applied Mathematics and Computation, 91(1), 43-61.

90. Horne, C. (2001). Sociological perspectives on the emergence of norms. In Social norms (pp. 3-34). Russell Sage Foundation.

91. Huff, A., \& Reger, R. (1987). A review of strategic process research. Journal of Management, 13(2), 211-236.

92. Jevons, S. (1988). The theory of political economy. Lincoln-Rembrandt Pub.

93. Kagami, M., Tsuji, M., \& Giovannetti, E. (2004). Information technology policy and the digital divide: Lessons for developing countries. Edward Elgar Publishing.

94. Kallinikos, J. (2006). Information out of information: On the self-referential dynamics of information growth. Information Technology \& People, 19(1), 98-115.

95. Kandampully, J. (2002). Innovation as the core competency of a service organisation: The role of technology, knowledge and networks. European Journal of Innovation Management, 5(1), 18-26.

96. Katz, R., Vaterlaus, S., Zenhausern, P., Suter, S., \& Mahler, P. (2009). The impact of broadband on jobs and the German economy. Technical Report, Deutsche Telekom AG.

97. Kelley, M. (1994) Productivity and information technology: The elusive connection. Management Science, 40, 1406-1425.

98. Koestler, A. (1967). The ghost in the machine. Springer.

99. Kohler, W. (1947). Gestalt psychology: An introduction to new concepts in modern psychology. New York: Liveright.

100. Koutroumpis, P. (2009). The economic impact of broadband on growth: A simultaneous approach. Telecommunications Policy, 33(9), 471-485.

101. Lawrence, K. (2009). Internet-based community networks: Finding the social in social networks. In J. Golbeck (Ed.), Computing with social trust, human-computer interaction series (pp. 313-331). London: Springer.

102. Lee, S., \& Treacy, M. (1988). Information technology impacts on innovation. R\&D Management, 18(3), 257-271.

103. Leff, N. (1984). Externalities, information costs, and social benefit-cost analysis for economic development: An example from telecommunications. Economic Development and Cultural Change, 32(2), 255.

104. Lehr, W., Gillett, S., Osorio, C., \& Sirbu, M. (2006). Measuring broadband's economic impact. Broadband properties (pp. 12-24).

105. Levy, A., \& Weld, D. (2000). Intelligent internet systems. Artificial Intelligence, 118(1-2), $1-14$. 
106. Lucking-Reiley, D. (2000). Auctions on the internet: What's being auctioned, and how? Journal of Industrial Economics, 48(3), 227-52.

107. Madden, G., \& Savage, S. (1998). CEE telecommunications investment and economic growth. Information Economics and Policy, 10(2), 173-195.

108. Madden, G., \& Savage, S. (2000). Telecommunications and economic growth. International Journal of Social Economics, 27(7/8/9/10), 893-906.

109. Madon, S. (1992). Computer-based information systems for development planning: The significance of cultural factors. Journal of Strategic Information Systems, 1(5), 250-257.

110. Madureira, A., Baken, N., \& Bouwman, H. (2010). Origin of value through information networks: A framework from an evolutionary holonic perspective. In Proceedings of the 18th Biennial conference of the international telecommunications society. Tokyo, Japan. Distinguished as one of the best student papers.

111. Madureira, A., den Hartog, F., Silva, E., \& Baken, N. (2010). Model for trans-sector digital interoperability. In Proceedings of the 6th international conference interoperability for enterprise software and applications. Springer-Verlag.

112. Madureira, A., van Boven, E., \& Baken, N. (2009). Towards systematic development of transsector digital innovations. In Proceedings of the international conference on infrastructure systems and services. IEEE.

113. Malone, T., \& Crowston, K. (1994). The interdisciplinary study of coordination. ACM Computing Surveys, 26(1), 87-119.

114. March, J., \& Simon, H. (1958). Organizations. New York: John Wiley.

115. Martin, J. (1992). Cultures in organizations: Three perspectives. Oxford University Press.

116. Marx, K., \& Engels, F. (1998). The communist manifesto. Signet Classics.

117. Melville, N., Kraemer, K., \& Gurbaxani, V. (1994). Review: Information technology and organizational performance: An integrative model of IT business value. MIS Quarterly, 28(2), 283-322.

118. Mentzer, J., DeWitt, W., Keebler, K., Min, S., Nix, N., Smith, C., et al. (2001). Defining supply chain management. Journal of Business Analysts, 22(2), 1-25.

119. Metcalfe, J. (1998). Evolutionary economics and creative destruction. New York: Routledge.

120. Milgrom, P. (1989). Auctions and bidding: A primer. Journal of Economic Perspectives, 3(3), $3-22$.

121. Miller, G. (1956). The magical number seven, plus or minus two: Some limits on our capacity for processing information. Psychological Review, 63, 81-97.

122. Mitra, S., \& Chaya, A. (1996). Analyzing cost-effectiveness of organizations: The impact of information technology spending. Journal of Management Information Systems, 13(2), 29-57.

123. Montanari, J. (1978). Managerial discretion: An expanded model of organization choice. The Academy of Management Review, 3(2), 231-241.

124. Nelson, R., \& Winter, S. (1985). Evolutionary theory of economic change. Belknap Press.

125. Neumann, O. (1989). Kognitive Vermittlung und direkte Parameterspezifikation: Zum Problem mentaler Repräsentation in der Wahrnehmung. Sprache und Kognition, 8, 32-49.

126. Neumann, O. (1990). Direct parameter specification and the concept of perception. Psychological Research, 52(2), 207-215.

127. Newell, B., \& Broder, A. (2008). Cognitive processes, models and metaphors in decision research. Judgment and Decision Making, 3, 195-204.

128. Nielsen Media (1997). Search engines most popular method of surfing the web. Technical report, Commerce Net/Nielsen Media.

129. OECD (2001). The development of broadband access in OECD countries. Technical Report, Organisation for Economic Co-operation and Development.

130. Ostrom, T. (1988). Computer simulation: The third symbol system. Journal of Experimental Social Psychology, 24, 381-392.

131. Payan, J. (2007). A review and delineation of cooperation and coordination in marketing channels. European Business Review, 19(3), 216-233.

132. Payne, J., Bettman, J., \& Johnson, E. (1993). The adaptive decision maker. Cambridge University Press.

133. Perez, C. (2003). Technological revolutions and financial capital: The dynamics of bubbles and golden ages. Edward Elgar Pub. 
134. Peters, R., \& Többen, H. (2005). A reference-model for holonic supply chain management. In Lecture Notes in Computer Science (Vol. 3593, pp. 221-232). Berlin: Springer.

135. Pettigrew, A. (1979). On studying organizational cultures. Academy of Management Review, 24(4), 570-581.

136. Piaget, J., \& Duckworth, E. (1970). Genetic epistemology. American Behavioral Scientist, 13(3), 459-480.

137. Popper, M. (2007). Normativity: Approaches, polemics, problems. Human Affairs, 17(1), 3-9.

138. Prahalad, C., \& Hamel, G. (1990). The core competence of the corporation. Harvard Business Review, 68(3), 79-91.

139. Price, G. (1995). The nature of selection. Journal of Theoretical Biology, 175(3), 389-396.

140. Read, S., Vanman, E., \& Miller, L. (1997). Connectionism, parallel constraint satisfaction processes, and gestalt principles: (Re)Introducing cognitive dynamics to social psychology. Personality and Social Psychology Review, 1(1), 26-53.

141. Röller, L., \& Waverman, L. (2001). Telecommunications infrastructure and economic development: A simultaneous approach. The American Economic Review, 91(4), 909-923.

142. Romanelli, E., \& Tushman, M. (1986). Inertia, environments and strategic choice: A quasiexperimental design for comparative-longitudinal research. Management Science, 32(5), 608621.

143. Rumelhart, D., \& McClelland, J. (1986). Parallel distributed processing: Explorations in the microstructure of cognition: Foundations (Vol. 1). Bradford: MIT Press.

144. Sambamurthy, V., Bharadwaj, A., \& Grover, V. (2003). Shaping agility through digital options: Reconceptualizing the role of information technology in contemporary firms. MIS Quarterly, 27(2), 237-263.

145. Samuels, W. (1993). Thorstein Veblen and the place of science. Society, 30(2), 76-82.

146. Santos, B. D., Peffers, K., \& Mauer, D. (1993). The impact of information technology investment announcements on the market value of the firm. Information Systems Research, 4(1), $1-23$.

147. Schiller, R. (2003). The new financial order. Princeton University Press.

148. Senge, P. (1984). The fifth discipline. New York: Doubleday.

149. Shannon, C. (1949). The mathematical theory of communication. University of Illinois Press.

150. Shideler, D., Badasyan, N., \& Taylor, L. (2007). The economic impact of broadband deployment in Kentucky. Regional Economic Development, 3(2), 88-118.

151. Shiu, A., \& Lam, P. (2008). Causal relationship between telecommunications and economic growth in China and its regions. Regional Studies, 42(5), 705-718.

152. Shubik, M. (1971). The dollar auction game: A paradox in noncooperative behavior and escalation. Journal of Conflict Resolution, 15(1), 109-111.

153. Simon, D., \& Holyoak, K. (2002). Structural dynamics of cognition: From consistency theories to constraint satisfaction. Personality and Social Psychology Review, 6(4), 283-294.

154. Simon, H. (1956). Rational choice and the structure of the environment. Psychological Review, 63(2), 129-138.

155. Sin, L., Tse, A., \& Yim, F. (2005). CRM: Conceptualization and scale development. European Journal of Marketing, 39(11/12), 1264-1290.

156. Sircar, S., Turnbow, J., \& Bordoloi, B. (2000). A framework for assessing the relationship between information technology investments and firm performance. Journal of Management Information Systems, 16(4), 69-97.

157. Smith, A. (1776). Wealth of nations. Prometheus Books.

158. Smith, E., \& Conrey, F. (2007). Agent-based modeling: A new approach for theory building in social psychology. Personality and Social Psychology Review, 11(1), 87-104.

159. Solow, R. (1956). A contribution to the theory of economic growth. The Quarterly Journal of Economics, 70(1), 65-94.

160. Sridhar, K., \& Sridhar, V. (2004). Telecommunications infrastructure and economic growth: Evidence from developing countries. Working Papers 04/14, National Institute of Public Finance and Policy.

161. Stevenson, W., \& Greenberg, D. (2000). Agency and social networks: Strategies of action in a social structure of position, opposition, and opportunity. Administrative Science Quarterly, 45(4), 651-678. 
162. Stewart, J. (1996). Cognition = life: Implications for higher-level cognition. Behavioural Processes, 35(1-3), 311-326.

163. Stiroh, K. (2002). Information technology and the U.S. productivity revival: What do the industry data say? American Economic Review, 92(5), 1559-1576.

164. Swidler, A. (1986). Culture in action: Symbols and strategies. American Sociological Review, 51(2), 273-286.

165. Swidler, A. (1997). Talk of love: How Americans use their culture. Chicago University Press.

166. Thagard, P. (1989). Explanatory coherence. Behavioral and Brain Sciences, 12(3), 435-466.

167. Thatcher, M., \& Oliver, J. (2001). The impact of technology investments on a firm's production efficiency, product quality, and productivity. Journal of Management Information Systems, 18(2), 17-45.

168. Thompson, H., \& Garbacz, C. (2007). Mobile, fixed line and internet service effects on global productive efficiency. Information Economics and Policy, 19(2), 189-214.

169. Thompson, H., \& Garbacz, C. (2008). Broadband impacts on state GDP: Direct and indirects impacts. International Telecommunications Society 17th Biennial Conference, Canada.

170. Umpleby, S. (2007). Physical relationships among matter, energy and information. Systems Research and Behavioral Science, 24(3), 369-372.

171. Van Alstyne, M. (1999). A proposal for valuing information and instrumental goods. In ICIS '99: Proceedings of the 20th international conference on information systems (pp. 328-345). Association for Information Systems.

172. Veblen, T. (1900). The preconceptions of economic science. Quarterly Journal of Economics, 14(2), 240-269.

173. Verhagen, T., \& Dolen, W. (2009). The influence of online store characteristics on consumer impulsive decision-making: A model and empirical application. Serie Research Memoranda 0046, VU University Amsterdam, Faculty of Economics, Business Administration and Econometrics.

174. Wade, M., \& Hulland, J. (2004). The resource-based view and information systems research: Review, extension, and suggestions for future research. MIS Quarterly, 28(1), 107-142.

175. Weiss, A. (2009). Smart infrastructure matches supply and demand. netWorker, 13(3), 18-25.

176. Wicklund, R., \& Brehm, J. (1976). Perspectives on cognitive dissonance. Hillsdale: Lawrence Erlbaum.

177. Wilson, C. (1996). Instruments and ideologies: The social construction of knowledge and its critics. American Philosophical Quarterly, 33(2), 167-178.

178. World Bank (1998). Telecommunications sector review. Technical Report 18455-LE, World Bank.

179. Zaheer, A., \& Soda, G. (2009). Network evolution: The origins of structural holes. Administrative Science Quarterly, 54(1), 1-31.

180. Zaheer, A., \& Venkatraman, N. (1994). Determinants of electronic integration in the insurance industry: An empirical test. Management Science, 40(5), 549-566.

181. Zand, F., \& van Beers, C. (2010). Performance effects of enterprise application software: New insights into the mediating role of innovation. In Proceedings of the 13th international business information management association (IBIMA) conference on knowledge management and innovation in advancing economies. 